\title{
La radicalización violenta de los jóvenes un reto en la construcción de sociedades seguras: una propuesta de tipología y escala de jóvenes vulnerables a procesos de radicalización violenta
}

\author{
Manuel Tamayo Sáez ; Isabel Bazaga Fernández²; Rut Bermejo Casado ${ }^{3}$
}

Recibido: 14/12/2020 / Aceptado: 08/07/2021

Resumen. El concepto de radicalización violenta está continuamente en revisión. Uno de los aspectos en discusión es la relevancia que tiene cada uno de los términos que lo componen: radicalización y violencia. Este trabajo bascula hacia el segundo término, intentando una aproximación al riesgo/vulnerabilidad a la radicalización violenta de los jóvenes desde la disposición de éstos a la violencia. El objetivo principal es explorar una tipología y una escala de jóvenes vulnerables a procesos de radicalización tomando como punto de partida la disposición de la juventud a la violencia. El interés de este ejercicio es segmentar el fenómeno de la radicalización violenta con objeto de diseñar políticas de prevención de la radicalización más efectivas. El colectivo estudiado es la población joven por ser el grupo de edad más vulnerable a los procesos de radicalización y sobre el que los efectos de las políticas pueden ser más eficaces y duraderos. Este colectivo y su predisposición a la violenta se estudia a partir de una encuesta on-line europea. Para la construcción de la tipología se utiliza el análisis de componentes principales y a partir de los tipos resultantes se diseña una escala de riesgo/vulnerabilidad a la radicalización violenta. Por último, se ilustra su utilidad con la sub-muestra de jóvenes españoles. La tipología y la escala de riesgo de radicalización o desarrollo de comportamientos violentos propuesta permite cambiar el punto de partida de las políticas de prevención de la radicalización violenta de la juventud y pasar el acento desde las ideologías políticas, religiosas y político-religiosas a las acciones, así proponer medidas y acciones de políticas que permitan enfocar el fenómeno de una manera diferente y holística. Se trata de un trabajo con un enfoque práctico y empírico que avanza en la clasificación de los jóvenes en riesgo o vulnerables a la radicalización violenta, además de proponer acciones y medidas de respuesta.

Palabras clave: Violencia, extremismo, juventud, política gubernamental.

[en] Violent radicalisation of young people as a challenge in building safe societies: a proposal for a typology and scale of young people vulnerable to violent radicalisation processes

\begin{abstract}
The concept of violent radicalisation is continually under review. One of the aspects under discussion is the relevance of each of its component terms: radicalisation and violence. This paper tilts towards the second term, attempting an approach to the risk/vulnerability to violent radicalisation of young people based on their disposition to violence. The main objective is to explore a typology and a scale of young people vulnerable to radicalisation processes taking as a starting point the youth's disposition to violence. The interest of this exercise is to segment the phenomenon of violent radicalisation in order to design more effective radicalisation prevention policies. The group studied is the young population, as it is the age group most vulnerable to radicalisation processes and the one on which the effects of policies can be most effective and long lasting. This group and its predisposition to violence is studied on the basis of a European on-line survey. Principal component analysis is used to construct the typology and a scale of risk/vulnerability to violent radicalisation is designed on the basis of the resulting types. Finally, its usefulness is illustrated with the sub-sample of young Spaniards. The proposed typology and scale of risk of radicalisation or development of violent behaviour allows us to change the starting point of policies to prevent the violent radicalisation of young people and to shift the emphasis from political, religious and politico-religious ideologies to actions, thus proposing policy measures and actions that allow us to approach the phenomenon in a different and holistic way. It is a work with a practical and empirical approach that advances in the classification of young people at risk or vulnerable to violent radicalisation, as well as proposing actions and response measures.
\end{abstract}

Keywords: Violence, extremism, youth, government policy.

Sumario. 1. Introducción. 2. Violencia y concepto de radicalización violenta. 3. El método para elaborar la tipología y la escala de riesgo/ vulnerabilidad a procesos de radicalización de jóvenes. 3.1. Los datos de partida sobre la disposición a la violencia. 3.2. Las dimensiones de la disposición a la violencia. 4.Tipología de jóvenes radicales y escala de riesgo de radicalización violenta. 4.1. Una tipología de jóvenes radicales. 4.2. La escala de riesgo de radicalización violenta. 5. Ilustración de la tipología y la escala con el caso de los jóvenes españoles. 6. Implicaciones de la tipología y la escala para el diseño de las políticas de prevención de la radicalización violenta de los jóvenes.

\footnotetext{
Universidad Rey Juan Carlos

manuel.tamayo@urjc.es

$2 \quad$ Universidad Rey Juan Carlos

isabel.bazaga@urjc.es

$3 \quad$ Universidad Rey Juan Carlos

rut.bermejo@urjc.es
} 
Cómo citar: Tamayo Sáez, M. et al. (2021): La radicalización violenta de los jóvenes un reto en la construcción de sociedades seguras: una propuesta de tipología y escala de jóvenes vulnerables a procesos de radicalización violenta, en Cuadernos de Gobierno y Administración Pública 8-1, 119-130.

\section{Introducción}

Siguiendo las "aproximaciones epidemiológicas" de las que se han tomado conceptos como "factores de riesgo", "enfermedad", "infección”, "agente externo", etc. (Moyano, 2011: 132-135), la propagación y extensión de la radicalización y el extremismo violento ha sido comparado en ocasiones con el comportamiento de un virus o una pandemia como la que actualmente sufre el mundo (Bermejo, 2020), un "virus psicológico" (Neumann, 2013: 873). Ese "virus" se identifica como las ideas radicales (políticas, político-religiosas o religiosas) que se extienden por contacto directo, van abriéndose camino en la familia, la sociedad, los grupos de amigos, etc., y producen efectos nocivos; efectos que son más nocivos en los individuos cuanto más constante y prolongada sea la exposición a ellas. Estos efectos son especialmente graves en la psique del individuo como relata Trujillo al describir la fase de adoctrinamiento ideológico en la que "se consigue instaurar nuevos repertorios comportamentales basados en nuevas creencias" (Trujillo, 2019: 100-101).

Sin embargo, esta visión del proceso de radicalización violenta, centrado en las ideas radicales y sus consecuencias, ha recibido duras críticas. Por un lado, aquellos que afirman que el acento en las ideas puede suponer un peligro para la libertad de expresión o marginar y victimizar determinadas ideologías. Por otro lado, aquellos que critican esta perspectiva por ser una estrategia "soft", por ejemplo, en la UE (Ruiz Díaz, 2017: 271). Entre las críticas, Neumann afirmaba en 2013 que "el enfoque europeo tiene sus puntos débiles. Puede ser demasiado vago y distraer la atención de los gobiernos de la prevención de la violencia como su principal prioridad" (Neumann, 2013: 893).

En este contexto, cabe recordar que las ideas son una parte de la ecuación de la violencia política y el terrorismo. La definición del terrorismo ha incorporado históricamente el concepto de violencia, violencia ejercida por el Estado (terrorismo de estado), violencia con fines políticos, violencia independentista... violencia que no solo es dirigida contra unos individuos, sino que implica daños al orden, la paz, la seguridad y las instituciones. Como analiza Rapoport (1999, 2004), dependiendo del lugar y del momento histórico la amenaza terrorista toma diferentes características. En el caso de Sudamérica se ha hablado mucho del terrorismo de estado durante las diferentes dictaduras del siglo XX, pero también en el siglo XXI, se ha calificado en ocasiones como "terrorismo" a la violencia estructural y sistémica contra la mujer (por ej. Rondon, 2003) o la "guerra de guerrillas urbanas".

Este trabajo no pretende centrarse en una discusión conceptual sobre el terrorismo ni en el papel que las ideas políticas, religiosas o político-religiosas juegan en la "conversión en terroristas", sino llamar la atención sobre esa segunda parte del binomio, menos estudiada, que es la violencia. El factor de la violencia (frente a la ideología), está sin duda presente en todos esos tipos de acciones que se engloban en el concepto de acciones terroristas y que se caracterizan por una indudable utilización de la violencia con diferentes fines políticos-sociales. Para este propósito, la presente investigación utiliza los datos de una encuesta online realizada en los siguientes países: Italia, Grecia, Austria, Polonia, Bélgica, Francia, España, Portugal, República Checa, Irlanda, Alemania y Dinamarca. La principal población destinataria es la de los jóvenes de 14 a 24 años, pero también incluye un grupo de edad superior (personas de 25 a 50 años) para tener resultados de referencia. En ella se incluyó una serie de preguntas sobre las actitudes hacia la violencia y su grado de aceptación en las sociedades europeas.

En base a los resultados de dicha encuesta, el objetivo de esta investigación es proponer una clasificación y agrupación de diferentes sujetos en relación al concepto de violencia. Para ello, se llevan a cabo diferentes tareas de investigación y análisis. En primer lugar, se busca la construcción de una tipología de jóvenes "violentos", como herramienta para avanzar en el estudio de la violencia en el ámbito del extremismo y la radicalización violenta. Se trata de crear una tipología descriptiva que siguiendo la teoría (Collier, Laporte y Seawright, 2008) aborda el concepto global de jóvenes radicales, incluye las variables en filas y columnas (disposición egocéntrica a la violencia y disposición sociotrópica a la violencia), crea un matriz $2 \times 2 \mathrm{y}$, a continuación, elabora y aborda la conceptualización de cuatro tipos "ideales" ubicados en las celdas, que corresponden a los 4 tipos de jóvenes radicales. Esas celdas serán los "contenedores de casos" y variables categóricas para la clasificación. Estos tipos "ideales" dan un significado conceptual a cada celda, correspondiendo a su posición con la fila y la columna de variables. Esta tipología permite, en último lugar, dar sentido empíricamente a un conjunto más completo y preciso de opiniones y características vertidos en la encuesta mencionada. En segundo lugar, se presenta una escala de riesgo/vulnerabilidad a procesos de radicalización para jóvenes que los sitúa en relación a la mayor probabilidad de recurrir a la violencia para la resolución de conflictos y/o problemas. A continuación, en tercer lugar, esta propuesta teórica es ilustrada a través de los resultados que, para el caso español, se recogieron en la encuesta referida y, por último, se acomete el trabajo de analizar las implicaciones que estos hallazgos pueden derivar en las políticas de prevención de la radicalización especialmente entre los jóvenes.

\section{Violencia y concepto de radicalización violenta}

Si se analizan los cambios en el terrorismo contemporáneo, y el paso a una nueva ola de terrorismo (Rapoport, 
2001) o la evolución del viejo al nuevo terrorismo (Crenshaw, 2008), la nueva era del terrorismo se caracteriza por ser más sangriento, por una menor dependencia en la financiación estatal, por nuevas formas de organización, campañas globales, y por la utilización de nuevas tecnologías de la comunicación (Jenkins, 2006: 117-118). En él la violencia o la amenaza del uso de violencia que se contiene en la definición del fenómeno (Hoffman 2006; Richardson 2006), siguen teniendo un papel clave en la persecución del objetivo político.

Cuando se observan algunas de las características propias del "nuevo" terrorismo, como las nuevas formas de organización de los grupos terroristas, cabe recordar que a pesar de presentar una "individualización" del terrorismo, que se percibe en la frecuencia de procesos de radicalización individuales o en los actores solitarios, el terrorismo sigue siendo un fenómeno inherentemente social y político (Crone, 2016: 597 ss). En este sentido, algunos autores han hablado de "la cultura de la violencia" que se enraíza en valores culturales o en la exposición a modelos sociales violentos, y que se establece como característica permanente de la sociedad, y que permite crear un marco en el que la violencia, violencia política y terrorismo encuentran una mejor justificación. Por ejemplo, Waldmann (2007) identifica el caso de Colombia como un ejemplo en el que la cultura puede explicar el uso de la violencia.

Para dar cuenta de la importancia cultural y social de la violencia, frente una interpretación de la pirámide de la radicalización (modelo de la escalera de Moghaddam (2005) o de la cinta transportadora de Baran (2005) entre otros) que concibe la radicalización como un proceso intelectual a través del cual un individuo estaría cada vez más hechizado por las ideas extremistas (radicalización cognitiva) para dar el paso a la acción (radicalización comportamental) (por ej. Wiktorowicz, 2005), han surgido diferentes trabajos que precisan o prefieren una "una interpretación de la pirámide que no es una teoría de etapas y que no requiere que cada nivel de la pirámide se alcance pasando por el nivel o los niveles inferiores a él" (Moskalenko y McCauley, 2009: 241). Estos autores realizan una distinción muy relevante para este trabajo: la disposición a participar en acciones políticas ilegales y violentas (radicalismo) no es lo mismo que el terrorismo: "los terroristas son el subconjunto de radicales que usan la violencia contra objetivos civiles." (Moskalenko y McCauley, 2009: 240). A pesar de que consideran importante analizar la relación entre el radicalismo y el terrorismo reconocen que no tienen posibilidad de estudiar la probabilidad de pasar de la violencia contra los militares o el gobierno a la violencia contra los civiles en su trabajo.

Entre los autores que han comenzado a destacar la importancia de la violencia en la radicalización violenta frente a la ideología o en conjunción con ella se encuentra Crone. Para este autor, "la ideología no es necesariamente una precondición para la violencia, sino que una experiencia previa con la violencia es con mayor frecuencia la precondición para adoptar una ideología extremista (Crone, 2016: 598). Este tipo de autores interpela la consideración de los procesos de radicalización divididos internamente en dos etapas: una de radicalización ideológica y otra posterior de radicalización del comportamiento, ya que esa transformación del comportamiento que lleva a una condición en la que una persona acepta el uso de la violencia o está dispuesto a perpetrarla, no iría necesariamente en segundo lugar, sino que su orden parece revertirse. El estudio de los "ambientes radicales violentos" (violent extremist milieu) acoge esta idea.

Crone, va más allá que otros autores que sostienen que la ideología no es necesariamente una condición previa para la violencia (Horgan y Taylor, 2011; McCauley y Moskalenko, 2008) para sugerir que "la violencia puede, por el contrario, ser una condición previa para comprometerse con la ideología extremista". Esa "experiencia de violencia" (tras la desinhibición violenta) también es destacada en el ámbito psicológico como un punto de inflexión a partir del cual es más difícil la "desradicalización" de los individuos (Victoroff, 2005; Trujillo-Mendoza, 2019). Con esta misma orientación han surgido diferentes líneas de trabajo que tratan de explicar por qué las cárceles son lugares de radicalización o por qué existe un nexo entre la criminalidad y el terrorismo (Basra et al., 2016; Kupatadze y Argomaniz, 2019). Todos estos autores coinciden en que "no es la convergencia de criminales y terroristas como organizaciones sino de sus redes sociales, entornos o medios ... Los grupos criminales y terroristas han llegado a reclutar dentro del mismo grupo de personas, creando (a menudo sin querer) sinergias y solapamientos que tienen consecuencias en la forma en que los individuos se radicalizan y operan" (Basra et al., 2016: 11).

Este trabajo se sitúa en un punto intermedio en estos debates teóricos ya que, aceptando la relevancia de la violencia, y centrando su enfoque en la "tendencia" y "justificación" de la violencia por parte de los jóvenes, no niega que la violencia sea, en contraposición a la agresividad, una acción "premeditada e intencional por parte de quien la genera" (Trujillo, et al. 2006: 277). Lo que busca es llamar la atención acerca de una posible "ideología de la violencia" que más allá de las ideologías políticas, político-religiosas o religiosas sirve en sí misma para justificar la violencia. Se sitúa, por lo tanto, en la línea de Barlett et al. que afirmaban que "... aquellos que dan el paso a la violencia frecuentemente han seguido un proceso de radicalización caracterizado por una cultura de la violencia, presión del grupo de pares, y un código de honor interno en el que la violencia puede ser una ruta para obtener estatus" (Barlett, et al., 2010: 12).

En este contexto la ideología es el "conjunto de reglas comunes y ampliamente acordadas que asume una persona y que le ayuda a regular y determinar su conducta" (Trujillo, et al, 2006: 281) y cuando entre esas reglas y valores se encuentra el uso de la violencia cualquier proceso de radicalización violenta pueda ser más probable o incluso más rápido. Estos jóvenes no concebirían la violencia como una elección racional, sino que su comportamiento violento estaría asentado en una "cultura de la violencia" y un sistema de valores que acepta el uso de la violencia, incluso, hace recomendable su utilización en ciertos contextos. La violencia sería justificable para defender sus "valores sagrados" (Gómez, et al.: 2016). 
Estos jóvenes se alejan del modelo propuesto por Nesser (2015) que habla de jóvenes que "muestran tendencias violentas desde la adolescencia temprana, a menudo tienen un trasfondo criminal y problemático".

En este sentido, trata de indagar si los jóvenes observados poseen ya narrativas o transmiten mensajes que legitimen la violencia justificando "la violencia en base a principios superiores ... (valores morales, símbolos, normas, roles, etc.)" (Trujillo-Mendoza, 2019: 102) por lo que cualquier contacto con un grupo/individuo adoctrinador puede ser más peligrosa que en otros jóvenes. El objetivo final de este trabajo es crear una tipología de jóvenes "propensos" a la violencia, o cuyo riesgo de participar en acciones violentas si entran en contacto con algún agente radicalizador, es mayor por tener aceptado el uso de la violencia en su sistema de valores o ideología. Las tipologías son un instrumento clásico en las ciencias sociales. En este caso se apuesta por la creación de una tipología empírico-inductiva a partir de los resultados de una encuesta. Así, se buscan las dimensiones clave que permitan identificar los subtipos de individuos. Esta tipología, y la conceptualización de sus tipos esenciales permitirá proponer una escala de riesgo/vunerabilidad de los jóvenes ante agentes o grupos radicalizadores.

\section{El método para elaborar la tipología y la escala de riesgo/vulnerabilidad a procesos de radicalización de jóvenes}

La encuesta que sirve de base a este trabajo fue realizada en línea por Kantar Public Brussels a través del proveedor del panel Research Now en doce países europeos: Alemania, Austria, Bélgica, Dinamarca, Francia, Grecia, República Checa, Irlanda, Italia, Polonia, Portugal y España. La encuesta se realizó del 28 de febrero al 21 de marzo 2018. Se entrevistó a 12.013 personas en total (1.000 por país). Un representante nacional de 14 a 24 años (500 por país) y una muestra de referencia representativa a nivel nacional de los jóvenes de 25 a 50 años de cada país (500 por país) fueron sorteados utilizando cuotas de edad, género y región ${ }^{4}$.

A continuación, se analizan los datos presentes en la encuesta que indican una posible disposición a la violencia entre los jóvenes. A partir de las 7 variables seleccionadas y recogidas y con el fin de reducir el número de variables y la correlación entre ellas se realiza un análisis de componentes principales que permite analizar los dos componentes surgidos a la luz de las variables originales.

\subsection{Los datos de partida sobre la disposición a la violencia}

Para elaborar la tipología y la escala de riesgo de radicalización violenta se utilizan una sub-muestra de la referida encuesta, correspondiente al caso español $(\mathrm{N}=708)$.

Véase: D2.3 Survey Report European Youth and radicalisation analysis and recomendations for policymaking purpose, Proyecto PRACTICIES: Partnership Against Violent Radicalisation in Cities.
Algunos estudios psicológicos previos han estudiado la desinhibición violenta, entre los jóvenes (Moyano, 2011), utilizando cuatro items: "intenciones de violencia hacia uno mismo" (en el último mes he tenido el deseo de terminar con mi propia vida) o "hacia otros" (en el último mes he tenido el deseo de terminar con la vida de otros), "el odio hacia otros" (en el último mes he sentido odio hacia algunas personas), y "la exposición a modelos que favorecen la violencia" (mis amigos hablan continuamente de peleas y temas violentos) (Lobato et al., 2018). En este caso, el estudio incluye dos preguntas relacionadas con la disposición de los jóvenes a la violencia. La primera (tabla 1) interpela al entrevistado sobre su nivel de aceptación de la violencia. Cabe recordar la importancia de estas actitudes y la justificación de la violencia, aunque en el contexto de la violencia política se debe tener en cuenta que "la gran mayoría de los que justifican la violencia política nunca participarán en acciones de violencia política" (Moskalenko y McCauley, 2009: 257).

Tabla 1. Aceptación del uso de la violencia por los jóvenes españoles.

\begin{tabular}{|l|c|c|}
\hline \multirow{2}{*}{ ¿En qué medida es aceptable el uso de la violencia para usted? } \\
\hline & Frecuencias & $\%$ \\
\hline En muchas circunstancias & 22 & 3,1 \\
En determinadas circunstancias & 80 & 11,3 \\
Solo en circunstancias extremas & 277 & 39,1 \\
En ninguna circunstancia & 305 & 43,0 \\
NS & 17 & 2,4 \\
NC & 7 & 1,0 \\
\hline Total & $\mathbf{7 0 8}$ & $\mathbf{1 0 0}$ \\
\hline
\end{tabular}

Fuente: Elaboración propia.

La tabla anterior muestra que un 14,4 por ciento de los jóvenes entrevistados considera aceptable el uso de la violencia en muchas/determinadas circunstancias.

La segunda pregunta recogida en la encuesta es de mayor utilidad en la medida en que, mediante una escala de cuatro puntos, nos informa de la mayor o menor disposición de los entrevistados a emplear personalmente la violencia ante una serie de situaciones (tabla 2).

De mayor a menor disposición a emplear personalmente la violencia los resultados son los siguientes, al sumar las categorías "Si, totalmente" y "Si, en cierta medida": un 73,1 \% la emplearía para defender a sus amigos o a miembros de su familia; un 49,8\% para defender sus derechos; un 46,2\% para luchar contra la injusticia; un $27,8 \%$ para defender sus ideas y sus valores; un 23,8 $\%$ para defender a España, un 14,5\% para emprender acciones políticas o por convicción; un 11,2\% para defender su religión. Estos porcentajes muestran que la disposición a la violencia varía sensiblemente según los supuestos que se plantean.

\subsection{Las dimensiones de la disposición a la violencia}

En dicha encuesta se identifican siete indicadores distintos que hablan de un mismo fenómeno: la disposición 
Tabla 2. Disposición a la violencia de los jóvenes españoles.

\begin{tabular}{|c|c|c|c|c|c|c|c|}
\hline \multicolumn{8}{|c|}{ ¿Personalmente estaría dispuesto/a usar la violencia en las siguientes situaciones? } \\
\hline & $\begin{array}{c}\mathrm{Si}, \\
\text { totalmente } \\
\%\end{array}$ & $\begin{array}{c}\mathrm{Si} \text {, en cierta } \\
\text { medida } \\
\%\end{array}$ & $\begin{array}{c}\text { No, no } \\
\text { realmente } \\
\%\end{array}$ & $\begin{array}{c}\text { No, en } \\
\text { absoluto } \\
\%\end{array}$ & $\begin{array}{l}\text { NS } \\
\%\end{array}$ & $\begin{array}{l}\mathrm{NC} \\
\%\end{array}$ & $\begin{array}{c}\text { Total } \\
\%\end{array}$ \\
\hline Para defender sus ideas o valores & 7,5 & 20,3 & 30,5 & 38,3 & 2,0 & 1,4 & 100 \\
\hline $\begin{array}{l}\text { Para defender a amigos u otros miembros de su } \\
\text { familia }\end{array}$ & 29,5 & 43,6 & 13,3 & 10,6 & 2,1 & 0,8 & 100 \\
\hline $\begin{array}{l}\text { Para emprender una acción política o por } \\
\text { convicción }\end{array}$ & 2, & 11,7 & 28,2 & 53,0 & 3,2 & 1,0 & 100 \\
\hline Para defender sus derechos & 11,7 & 38,1 & 24,7 & 22,7 & 1,8 & 0,8 & 100 \\
\hline Para defender a España & 6,6 & 17,2 & 24,6 & 47,3 & 3,0 & 1,3 & 100 \\
\hline Para defender su religión & 3,4 & 7,8 & 22,6 & 61,3 & 2,4 & 2,5 & 100 \\
\hline Para luchar contra la injusticia & 10,7 & 35,5 & 29,7 & 20,2 & 2,7 & 1,3 & 100 \\
\hline
\end{tabular}

Fuente: Elaboración propia.

a la violencia de los jóvenes. Lo interesante sería saber si existe una estructura subyacente que los relacione y los agrupe en un número menor de dimensiones. Para ello, se somete los datos a un análisis de componentes principales que permitirá explorar si, efectivamente, la disposición a la violencia se resume en uno o en varios factores. El análisis de componentes principales arroja los siguientes resultados:

Tabla 3. Dimensiones de disposición a la violencia.

\begin{tabular}{|c|c|c|}
\hline $\begin{array}{c}\text { Matriz de } \\
\text { componentes rotados }\end{array}$ & Componente 1 & Componente 2 \\
\hline $\begin{array}{l}\text { Para defender sus } \\
\text { ideas o valores } \\
\text { Para defender amigos } \\
\text { o miembros de su } \\
\text { familia } \\
\text { Para emprender una } \\
\text { acción política o por } \\
\text { convicción } \\
\text { Para defender sus } \\
\text { derechos } \\
\text { Para defender España } \\
\text { Para defender su } \\
\text { religión } \\
\text { Para luchar contra la } \\
\text { injusticia }\end{array}$ & $\begin{array}{l}0,783 \\
0,399 \\
0,714\end{array}$ & $\begin{array}{l}0,777 \\
0,236\end{array}$ \\
\hline \multicolumn{3}{|c|}{$\begin{array}{l}\text { Método de extracción: análisis de los componentes } \\
\text { principales. } \\
\text { Método de rotación: Varimax con normalización Kaiser. } \\
\text { La rotación ha convergido en tres iteraciones. }\end{array}$} \\
\hline
\end{tabular}

Fuente: Elaboración propia.

El procedimiento de reducción de datos utilizado agrupa los siete indicadores de partida en dos factores que representan, según nuestra interpretación, dos dimensiones diferentes de disposición a la violencia. El componente 1, denominado en adelante disposición socio-trópica a la violencia, se vincula con motivos de carácter colectivo y con valores. En esta dimensión los individuos estarían más o menos dispuestos a emplear personalmente la violencia para defender ideas, convicciones, valores políticos, religiosos, identitarios, etc. Es una dimensión idealista de disposición a la violencia. El componente 2, que se llamará disposición egocéntrica a la violencia, refleja motivaciones de carácter particular y se asocia a intereses. En este caso, los individuos estarían más o menos dispuestos a emplear personalmente la violencia para defender a los suyos, sus derechos, y protegerse de las injusticias que les afectan. Es una dimensión de disposición a la violencia basada en intereses y motivaciones individuales. Hay dos variables - "Para defender sus ideas y sus valores" y "Para luchar contra la injusticia", que tienen presencia en los dos componentes, es decir se vinculan a las dos dimensiones de la disposición a la violencia, si bien es cierto que se asocian más al primero o al segundo componente, respectivamente.

\section{Tipología de jóvenes radicales y escala de riesgo de radicalización violenta}

\subsection{Una tipología de jóvenes radicales}

Si se combinan las dos dimensiones de disposición a la violencia identificadas, se puede trazar una tipología de jóvenes radicales, entendidos en función de su justificación del uso de la violencia, con cuatro posiciones. Los tipos serían los que se detallan en la figura 1.

A continuación, se ensaya una caracterización conceptual de los tipos propuestos. En primer lugar, los $\mathrm{Pa}$ cifistas combinan una disposición baja a la violencia en las dos dimensiones identificadas. Se trata de un segmento que, cuando se moviliza ante los conflictos y agravios que les afectan o en protesta por injusticias que observan, lo hacen mediante mecanismos de participación política convencional, recurriendo a vías institucionales y sin usar la fuerza. Muestran su desacuerdo con manifestaciones no violentas, sentadas, recogidas de firmas, resistencia pasiva, actos festivos, iniciativas que ayuden a centrar la atención del público, los medios y los actores políticos, y asociándose para tener voz y capacidad de representación. Ejemplos que ilustran este segmento son 
Figura 1. Tipología de radicales a partir de las dimensiones de disposición a la violencia.

\begin{tabular}{|l|l|l|l|}
\hline \multirow{2}{*}{ DIMENSIONES } & \multicolumn{2}{l|}{$\begin{array}{l}\text { DISPOSICIÓN } \\
\text { EGOCÉNTRICA A LA VIOLENCIA }\end{array}$} \\
\cline { 3 - 4 } \multicolumn{2}{|c|}{} & BAJA & ALTA \\
\hline $\begin{array}{l}\text { DISPOSICIÓN } \\
\text { SOCIOTRÓPICA } \\
\text { A LA VIOLENCIA }\end{array}$ & BAJA & PACIFISTA & AUTODEFENSIVOS \\
\cline { 3 - 4 } & ALTA & ALTRUISTAS & DOBLEMENTE AGRAVIADOS \\
\hline
\end{tabular}

Fuente: Elaboración propia.

el movimiento por los derechos de los homosexuales, las organizaciones feministas y el movimiento ecologista clásico. Lo que diferencia a los pacifistas del resto de segmentos identificados es, precisamente, su confianza en las soluciones institucionales, la participación y la no violencia como medios para la resolución de los agravios y las injusticias que les importan.

En segundo lugar, el segmento de los Autodefensivos combina una disposición alta a la violencia en la dimensión egocéntrica y baja en la dimensión socio-trópica. Se movilizan de forma reactiva, para resolver situaciones personales o ante medidas gubernamentales que entienden injustas y que les afectan directamente o a su entorno más inmediato. Dentro de este tipo se engloban, al menos dos subtipos: los resentidos y los indignados. El primer subtipo de los autodefensivos son los resentidos. Se trata de personas que se movilizan como reacción a agravios y humillaciones que sufren y se van acumulando en su interior, hasta un punto en que la única solución que consideran eficaz es vengarse de quienes les ofenden. Los adolescentes son particularmente sensibles a los agravios y las humillaciones personales. En algunos casos ejercen la violencia contra sí mismos, autolesionándose o suicidándose como forma de protesta y de resolución definitiva del sufrimiento que sienten. En otros casos castigan a quienes responsabilizan de su malestar: compañeros de estudios, acosadores, profesores, superiores, etc. El acceso a armas de fuego y otros medios para causar daño es un factor que multiplica la gravedad de las consecuencias de sus actos de venganza, como se ha visto en los tiroteos masivos ocurridos en institutos, universidades, centros de trabajo, etc.

El segundo subtipo es el de los indignados que son un segmento que se moviliza para intentar restaurar sus derechos y afrontar el trato injusto o la desatención por parte de las instituciones. Las palancas que les impulsan son muy diversas: cambios regulativos sectoriales, procesos de transición a la competencia, cambios tecnológicos, recortes sociales, subidas de precios públicos e impuestos, cambios drásticos de posición ante el consumo colectivo de bienes y servicios, etc. El efecto de todas ellas es el mismo: un sentimiento de privación relativa, de pérdida de derechos y oportunidades, de quedar relegados de las corrientes principales de la sociedad. Ejemplos que encarnan este segmento son las viejas clases medias en declive, trabajadores de sectores tradicionales que no pueden competir en un panorama dominado por las grandes plataformas de distribución de bienes y servicios, las comunidades rurales en retroceso, los trabajadores de industrias desmanteladas o deslocalizadas, etc.
Los Chalecos Amarillos en Francia son un retrato vivo de los indignados, su protesta se inicia por una subida de los impuestos a los carburantes. La Revolución de los Paraguas en Hong Kong, es un estallido social frente a un cambio en la normativa sobre extradición a China.

En tercer lugar, está el tipo Altruista, combina una disposición alta a la violencia en la dimensión sociotrópica, y baja en la dimensión egocéntrica. Incluiría a jóvenes idealistas que se movilizan por motivos comunitarios: la patria, la religión, causas sociales e ideas políticas. Se trata de personas que luchan por motivos que no les afectan personalmente, actuando por tanto de modo desinteresado llegando, en el extremo, a matar/ dar la vida por la causa que se sienten obligados a defender. El tipo altruista se basa en un sentido de misión, en un compromiso que les parece ineludible y que deben atender por cualquier medio, incluida la fuerza. Las emociones son la clave o, mejor dicho, las interacciones entre valores y emociones. Un ejemplo que encarna este tipo podría ser el de los Foreign Fighters: jóvenes que marcharon para luchar por el DAESH en Siria o Irak; o el de los Brigadistas Internacionales que vinieron a España como voluntarios para defender la República y luchar contra el fascismo. La causa, como se ve, puede ser acertada o no, es indiferente.

Por último, el conjunto de los "doblemente agraviados", son un segmento formado por individuos con una disposición alta a la violencia en las dos dimensiones identificadas. Se movilizan por la yuxtaposición de intereses y valores, por una mezcla de agravios a su persona y a la comunidad de la que se sienten parte. Este colectivo se construye, habitualmente, por oposición a otras comunidades o poderes a quienes hacen responsables de los agravios que padecen. La solución a sus problemas no puede ser individual si no colectiva, ligando su destino al de la comunidad a la que pertenecen: para salvarme yo tenemos que salvarnos todos, para liberarme yo tengo que liberar a todos de la opresión de que somos objeto. El enemigo puede ser occidente, Europa, otras naciones, el capitalismo salvaje o los extranjeros, dependiendo de si se habla de yihadistas, anti-europeístas, nacionalistas, antisistema o ultraderechistas. Todos ellos creen disponer de una solución definitiva, utópica, a la que se debe llegar empleando la fuerza si es preciso: el gobierno de dios, la independencia y la plena soberanía nacional, un nuevo orden social y económico mundial o una identidad libre de contaminación exterior. Se trata de alcanzar una situación nueva en la que, cesada la amenaza y las causas de la opresión, hay posibilidades de mejora y de futuro para todos. Muchas de estas soluciones utópicas 
toman como referencia un pasado mítico de la comunidad más feliz y pleno al que se desea volver. Los Homegrown Terrorists son un buen ejemplo de este tipo, los supremacistas blancos, también: unos y otros se sienten amenazados de forma personal y colectiva.

\subsection{La escala de riesgo de radicalización violenta}

Una vez descritos los tipos se puede elaborar una escala en la que se exprese la probabilidad de radicalización violenta/utilización de la violencia de los jóvenes. La escala reflejaría la prioridad que cada grupo debiera suponer para una política de prevención de la radicalización, y es un continuo de menor a mayor probabilidad de utilización de la violencia, en el que se puede situar a los tipos identificados anteriormente según se refleja en la figura 2.

Los pacifistas suponen el mínimo nivel de riesgo y el grupo de los doblemente agraviados los de mayor riesgo, al aunar las dos dimensiones de disposición a la violencia. En las posiciones intermedias, se encuentran los autodefensivos primero y después a los altruistas. Respecto a los detalles de los tres grupos de riesgo. De los dos grupos que conforman el tipo autodefensivo, el de los resentidos es el de menor riesgo para los demás, aunque seguramente sea el que genera más víctimas entre la juventud al recurrir algunos de ellos al suicidio como medio para terminar con las injusticias, abusos y humillaciones de que son objeto.

Los indignados pueden llegar a ser grupos numerosos que se conforman y desaparecen al albur de la coyuntura. Su comportamiento depende, principalmente, de las respuestas que obtienen desde las instituciones, modulando la presión que ejercen a la vista de la receptividad del gobierno a sus demandas, combinando vías legales e institucionales con el uso de la fuerza según convenga. Dependiendo del nivel de formalización y estructuración interna del movimiento, incluida la existencia de liderazgos reconocidos, variará mucho la probabilidad de que se descontrolen sus acciones y escalen en el uso la violencia. Los grupos menos organizados y sin interlocutores son más imprevisibles y también más inconstantes. Otra variable clave para calibrar sus respuestas es lo difuso o concreto de sus demandas, o lo que es lo mismo, del agravio que sienten. Si las razones que les mueven son claras y concentradas, la gestión del problema es más sencilla, si se trata de causas difusas y sin un "enemigo" identificable enfrente, la situación se puede complicar más, el movimiento inicial puede ser capturado y utilizado de forma oportunista para vehicular cualquier otro descontento.

Los indignados emplean el espacio público como escenario para la expresión de su malestar: el centro de la ciudad es el lugar preferido por la atención que recibe cualquier evento que altere su normal funcionamiento. Las principales plazas y arterias que vertebran la ciudad, las infraestructuras del transporte, los edificios gubernamentales y otros sitios emblemáticos del tejido urbano son las localizaciones típicas de sus acciones. Ejercen, generalmente, formas de violencia de baja/media intensidad: manifestaciones no autorizadas, escraches a dirigentes y autoridades públicas, sabotajes, boicots, huelgas, presiones a grupos que no se suman al movimiento, desobediencia, enfrentamientos con las fuerzas del orden, vandalismo, pillaje y violencia en las cosas, alteración del orden público, etc. Circunstancialmente estos actos pueden dar lugar a daños personales irreversibles. El riesgo de que recurran al terrorismo es bajo, máxime si el conflicto sigue encapsulado en torno a intereses de parte.

Los altruistas presentan un riesgo de radicalización violenta más elevado que los anteriores, son un segmento reducido y de él solo una minoría son los que intentan y menos aun los que consiguen llevar sus fantasías justicieras a la realidad. Los altruistas actúan con todo el fervor y la determinación que solo las convicciones alientan. Una disposición alta a la violencia, unida a una mezcla desfavorable de factores protectores y factores de riesgo de radicalización, junto a unas circunstancias apropiadas, son los ingredientes que abonan el paso de las ideas salvíficas a las conductas violentas para implantarlas. Este segmento puede recurrir a formas de violencia de alta intensidad, incluida la lucha armada y la comisión de atentados con víctimas. Este grupo, por tanto, debe ser prioritario para la política de prevención de la radicalización violenta de la juventud.

Los altruistas son blancos perfectos para las redes que captan y adoctrinan a jóvenes y les conducen hacia sus metas y objetivos ilícitos. En este segmento el adoctrinamiento se facilita y su efecto se multiplica por la ausencia de experiencia personal sobre las realidades y asuntos a los que se suman: luchan por causas y grupos que solo conocen de modo superficial y a través de discursos manipulados y narrativas que distorsionan la realidad, sin posibilidad de contrastación por su parte. Si el altruista se auto-radicaliza la ausencia de experiencias directas es incluso peor: es el propio individuo el que construye una narrativa justificativa a la medida de su pulsión de castigar las injusticias. Esto no les ocurre a los doblemente agraviados, o no con la misma facilidad, al contar con información que proviene de su propia experiencia.

La única ventaja que plantea este tipo es que, tanto quienes les intentan captar como ellos mismos, dejan muchas huellas que informan del proceso de radicalización al que se están sometiendo y, por tanto, se puede intervenir en distintos momentos del proceso. Los adoctrina-

Figura 2. Escala de riesgo de radicalización.

\begin{tabular}{|l|l|l|l|}
\hline PACIFISTAS & AUTODEFENSIVOS & ALTRUISTAS & $\begin{array}{l}\text { DOBLEMENTE } \\
\text { AGRAVIADOS }\end{array}$ \\
\hline Menor probabilidad de radicalización violenta $\rightarrow$ & \multicolumn{2}{|c|}{ Mayor probabilidad de radicalización violenta } \\
\hline
\end{tabular}


dores no siempre tienen éxito y son rechazados, desenmascarados y detectados por las autoridades, las familias, etc. Los jóvenes idealistas radicalizados no siempre hacen acopio de la determinación suficiente como para pasar a la acción a pesar de sus inclinaciones violentas, pero puede que revelen sus intenciones a terceros. Si se deciden a actuar, en ocasiones se limitarán a acciones violentas de baja intensidad que sirvan para centrar en ellos la atención de los servicios de inteligencia. Cuando quieren pasar a mayores, es posible que les falten los medios o las oportunidades para hacerlo, pero los movimientos para procurárselos y adaptarse a las circunstancias generan pistas que se pueden seguir. Los altruistas y quienes tratan de impulsarles a cometer actos violentos no son completamente opacos ante la mirada de los amigos, las familias, los profesionales que les prestan servicios, la policía, etc.

Los doblemente agraviados son los más proclives al empleo de la fuerza al combinar la disposición egocéntrica y la socio-trópica a la violencia. La radicalización de este grupo es la más difícil de evitar al fundirse motivos individuales y colectivos, al mezclarse y reforzarse mutuamente intereses que justifican la movilización y valores superiores que la legitiman. Esta mezcla da lugar a compromisos personales de gran solidez con la causa por la que se decide luchar, lo que dificulta su posible des-radicalización. Abandonar la causa supone renunciar a ciertos beneficios e intereses personales y además traicionar a la colectividad.

Este segmento, minoritario también afortunadamente, es el perfil al que recurren los líderes de los movimientos sociales, religiosos, los partidos y movimientos políticos extremistas, etc., como fuerza de choque para sus estrategias. Son utilizados como agentes para activar y avivar los conflictos, elevar la tensión y polarizar a la comunidad, movilizar a sectores simpatizantes, impedir las iniciativas de los opositores, amedrentar y silenciar a las voces críticas, etc.

Los líderes señalan los objetivos y modulan la intensidad de la fuerza a emplear, organizando y supervisando los procesos o mediante llamamientos generales a la acción violenta que son administrados de forma autónoma por los seguidores según los medios y las oportunidades que se les presenten. El papel de los líderes es clave en la radicalización violenta de este segmento. $\mathrm{Su}$ influencia sobre los seguidores se puede ejercer por distintos medios: adoctrinamiento, reclutamiento e integración en grupos organizados y jerarquizados, coordinación entre grupos violentos afines que se conectan formando redes, llamados a colectivos simpatizantes que coquetean con la violencia, narrativas y discursos para fomentar el compromiso y la acción directa de grupos auto-organizados individuos aislados, etc.

El riesgo que corren las organizaciones que impulsan a estos grupos radicales es perder el control sobre ellos y que se conviertan en una suerte de milicias, de comandos o de lobos solitarios que terminan operando de forma autónoma. La llegada al poder de partidos, movimientos políticos y líderes extremistas potencia la probabilidad de que los doblemente agraviados se radicalicen y cometan actos violentos. Este segmento puede recurrir a la fuerza en todos sus niveles incluida la lucha armada y los atentados si se dan las circunstancias y los medios para ello.

\section{Ilustración de la tipología y la escala con el caso de los jóvenes españoles}

Si se aplica la tipología y la escala de utilización de la violencia/radicalización violenta al caso de los jóvenes españoles, el resultado es el que se detalla en la figura 3.

Los resultados son razonablemente alentadores ya que los jóvenes con una orientación sociotrópica a la violencia presentan mayoritariamente una disposición baja a la violencia y los que manifiestan una orientación egocéntrica se distribuyen casi por igual entre quienes mantienen una disposición alta y baja a la violencia.

En la figura 4 se recogen los datos de la escala de riesgo de radicalización violenta.

Figura 3. Tipología de jóvenes radicales en España.

\begin{tabular}{|c|c|c|c|c|}
\hline \multirow{2}{*}{\multicolumn{2}{|c|}{ DIMENSIONES }} & \multicolumn{2}{|c|}{$\begin{array}{l}\text { DISPOSICIÓN } \\
\text { EGOCENTRICA A } \\
\text { LA VIOLENCIA }\end{array}$} & \multirow[t]{2}{*}{ TOTAL } \\
\hline & & $B A J A$ & ALTA & \\
\hline \multirow{3}{*}{$\begin{array}{c}\text { DISPOSICIÓN } \\
\text { SOCIOTROPICA } \\
\text { A LA VIOLENCIA }\end{array}$} & BAJA & $\begin{array}{c}217 \\
(30,6 \%) \\
\text { PACIFISTAS }\end{array}$ & $\begin{array}{c}292 \\
(41,2 \%) \\
\text { AUTODEFENSIVOS }\end{array}$ & $\begin{array}{c}509 \\
(71,9 \%)\end{array}$ \\
\hline & ALTA & $\begin{array}{c}92 \\
(13,0 \%) \\
\text { ALTRUISTAS }\end{array}$ & $\begin{array}{c}107 \\
(15,1 \%) \\
\\
\text { DOBLEMENTE } \\
\text { AGRAVIADOS }\end{array}$ & $\begin{array}{c}199 \\
(28,9 \%)\end{array}$ \\
\hline & TOTAL & $\begin{array}{c}309 \\
(43,6 \%)\end{array}$ & $\begin{array}{c}399 \\
(56,4 \%) \\
\end{array}$ & 708 \\
\hline
\end{tabular}

Fuente: Elaboración propia. Método de cálculo: dicotomización de las variables generadas a partir de cada factor, estableciendo una puntuación que asigna los casos a una de dos categorías $(0=\mathrm{BAJA} ; 1=\mathrm{ALTA})$ a partir del análisis de la distribución de cada variable y cálculo de tabla de contingencia. 
Figura 4. Escala de riesgo de radicalización violenta de los jóvenes españoles

\begin{tabular}{|c|c|c|c|c|}
\hline PACIFISTAS & $\begin{array}{c}\text { AUTODEFENSIVOS } \\
(217)\end{array}$ & ALTRUISTAS & $\begin{array}{c}\text { DOBLEMENTE } \\
\text { AGRAVIADOS } \\
(107)\end{array}$ & TOTAL \\
$30,6 \%$ & $(292)$ & $(92)$ & $15,1 \%$ & $10 \%$ \\
\hline \multicolumn{2}{|l|}{ Menor probabilidad de radicalización violenta } & $13,0 \%$ & Mayor probabilidad de radicalización violenta & \\
\hline
\end{tabular}

Fuente: Elaboración propia.

La figura 4 muestra como el grupo más numeroso es el de los autodefensivos, lógico si se tiene en cuenta que engloba a quienes están dispuestos a defender a la familia y amigos, sus derechos, etc. El siguiente grupo en tamaño, es el grupo de los jóvenes pacifistas. A continuación, están a los altruistas y a los doblemente agraviados con cuantías muy similares.

\section{Implicaciones de la tipología y la escala para el diseño de las políticas de prevención de la radicalización violenta de los jóvenes}

Centrar la atención en la disposición a la violencia a la hora de enfocar la prevención de la radicalización de los jóvenes lleva, naturalmente, a un conjunto de medidas de política pública útiles para todos los tipos identificados. Esas medidas se pueden agrupar entorno a tres objetivos básicos. Primero, acciones con la finalidad de detectar actitudes y predisposiciones a la violencia como son (1) diseñar herramientas que permitan detectar de forma temprana la propensión a la violencia de los niños y adolescentes y (2) emprender la elaboración de instrumentos que sirvan para apreciar el riesgo de que los jóvenes recurran a la violencia como medio para sus fines. Un segundo grupo de medidas se dirigiría a la prevención temprana de la radicalización violenta. Con este fin se debe buscar: (3) la promoción de una cultura de la paz y la no violencia en las instituciones educativas, (4) el fomento de las relaciones intrafamiliares e interpersonales no autoritarias, (5) la difusión de modelos de masculinidad no vinculados a la agresividad, la fuerza y la dominación (6) la mejora de la capacidad de los niños y los adolescentes para gestionar sus emociones, afrontar la frustración, la ira, el miedo, la desesperanza, etc. (7) así como dotar a los jóvenes de habilidades y herramientas vinculadas al pensamiento crítico que les permitan desvelar los objetivos espurios de quienes les llaman a defender causas usando la fuerza, o justificándola, (8) Reforzar las capacidades de los niños y los jóvenes para evaluar correctamente las consecuencias, para sí mismos y para los demás, del uso de la fuerza en sus relaciones cotidianas, (9) aumentar la sensibilidad y la receptividad de los gobiernos a la agenda de temas y las preferencias de políticas públicas de los jóvenes y (10) mejorar la capacidad de análisis de los decisores públicos y legisladores, para que puedan valorar adecuadamente las consecuencias para los niños y la juventud de las decisiones que adoptan y las normas que aprueban. Por último, y en previsión del riesgo de ser captados y adoctrinados se- ría recomendable diseñar respuestas tendentes a frenar/ detener el avance de los procesos de radicalización de los jóvenes con acciones y medidas que (11) controlen e impidan la difusión de discursos condescendientes, que admitan, justifiquen o promuevan el uso de la violencia entre los jóvenes, (12) fomenten la resolución de conflictos a través de la discusión, la negociación, la cooperación y la empatía, (13) mejoren el conocimiento y la utilización de las vías institucionales para la prosecución de intereses, la defensa de los derechos individuales, la lucha contra las injusticias, etc., (14) promuevan y desarrollen los medios y vías de participación política y social de los jóvenes en los asuntos que les interesan y también (15) mejoren y aprovechen para la política de prevención de la radicalización, los programas específicos para intervenir con jóvenes que muestran conductas agresivas, violentas o delincuenciales.

Además de estas 15 medidas que, en un sentido amplio, sirven para la prevención de la radicalización en toda la población joven, la tipología permite pensar en orientaciones e instrumentos de política pública para cada uno de los segmentos de radicales. Así, por ejemplo, los pacifistas son el segmento menos acuciante para la política de prevención de la radicalización y que habría que estudiar en detalle para entender la mezcla de valores, ideología, situación personal, etc., que se asocia a su baja o nula disposición a la violencia, con objeto de elaborar teorías útiles para abordar el tratamiento del resto de grupos. Este grupo de jóvenes es un apoyo fundamental para las políticas de prevención de la radicalización al mostrar que es posible perseguir metas, intereses y valores por medios no violentos. El apoyo a las vías pacíficas aumenta con su eficacia y la valoración de la eficacia depende, en parte, de las expectativas de logro de partida. En este sentido, gestionar las expectativas de la juventud -qué se puede conseguir en una sociedad plural y diversa-y, mejorar la eficacia de las vías pacíficas para la resolución de conflictos, son elementos clave para la prevención de la radicalización.

La política de prevención de la radicalización violenta, debiera distinguir internamente los dos grupos que hemos identificado al interior de los autodefensivos: los resentidos y los indignados, dado que plantean desafíos muy distintos. Los primeros tienden a operar en solitario, los segundos acaban por reconocerse en otros y adoptar posiciones de grupo. Es posible que haya una pasarela entre ambos subgrupos: resentidos que pasan a ser indignados, jóvenes que toman conciencia de que su problema no es solo algo suyo, sino que afecta a una categoría de gente a la que pertenecen. 
Los jóvenes resentidos son difíciles de identificar. Sufren los agravios de forma silenciosa hasta que estallan dañándose a sí mismos y/o a aquellos que les tratan de forma injusta, con tal de liberarse de la presión que sienten. Los jóvenes que sufren bullying, son el ejemplo que encarna esta situación. Es posible que envíen señales sobre su situación, pero o no son detectadas o no son atendidas convenientemente. Las prioridades de la política de prevención de la radicalización violenta para este grupo son: la detección temprana de los casos y el tratamiento tanto de las víctimas de acoso como de los acosadores. La familia, la escuela y el espacio on line son los contextos principales en los que abordar el problema. Como se dijo con anterioridad, en sociedades en las que los jóvenes tienen acceso a armas de fuego, los jóvenes resentidos pueden ser particularmente peligrosos.

Los jóvenes indignados, pueden haber sido antes pacifistas hartos de ver que los medios pacíficos no les aproximan a sus objetivos. Los activistas por los derechos de los animales en ocasiones recurren a la violencia, con mayor o menor intensidad, como medio para llamar la atención y forzar respuestas institucionales. La conversión de indignados en doblemente agraviados es otra posibilidad: los jóvenes que protestan por el cambio climático, se sienten ya directamente afectados por la inacción y falta de compromiso de los gobiernos, las empresas y la generación que les precede. Evitar el paso entre "tipos" debe ser una de las prioridades de la política de prevención de la radicalización. La ventaja a la hora de tratar al segmento de los autodefensivos es que los agravios que se generan por la afectación de un interés se desactivan rápidamente al cesar su causa: el gobierno da marcha atrás a una medida considerada injusta y las protestas violentas en la calle, se extinguen. Las protestas violentas vinculadas a recortes en derechos sociales, subidas de precios públicos, etc., suelen obedecer a errores de cálculo de las autoridades, que no prevén las reacciones de los colectivos afectados a las medidas que adoptan. La resistencia masiva de los afectados obliga a derogar las decisiones más polémicas. Asimismo, los conflictos en torno a intereses, por su propia naturaleza, se pueden tratar de forma incremental y mediante negociaciones, admitiendo de forma parcial demandas de los agraviados, difiriendo ciertos aspectos para el futuro, etc. La admisión parcial de las demandas de los indignados fractura la unidad del colectivo, fomenta las disensiones y resta apoyos a las soluciones violentas. La existencia de liderazgos claros y de ciertas estructuras al interior de los colectivos de indignados, son variables clave que ayudan a la resolución negociada de los conflictos en torno a intereses: hace falta una contraparte con la que llegar a acuerdos.

Los altruistas son un grupo particularmente sensible a lo que ocurre en el entorno, siempre a la busca de una buena causa por la que luchar. Adoptan posiciones extremistas en las ideas con facilidad y son susceptibles de manipulación por terceros $\mathrm{y}$, por ende, de captación para fines violentos y terroristas. La teoría de la oferta y la demanda es de plena aplicación en este caso: busco una causa que de sentido a mi deseo de hacer justicia y alguien me la ofrece y me allana el camino para emprender la lucha.
Ante este panorama, la política de prevención de la radicalización violenta debiera disponer de una suerte de "agenda viva" de temas que pudieran centrar la atención de este tipo de jóvenes. Para cada tema convendría elaborar un relato que les explique la realidad de los conflictos que subyacen, los objetivos de las partes y los intereses que persiguen, las vías institucionales para atenderlos, las mentiras y subterfugios que emplean quienes les animan a usar la fuerza para resolverlos y las estrategias para hacerles frente y no caer en sus redes. Se trata de encauzar su energía idealista y sus emociones hacia vías pacíficas de participación y lucha contra las injusticias. Los temas de la agenda post-materialista, los vinculados con conflictos internacionales, y cualquier asunto que afecte a la justicia y la igualdad y provoque reacciones emotivas fuertes, tienen un alto potencial de movilización para este segmento de la juventud. Paralelamente, la prevención tendrá que ver con la monitorización y el control de grupos organizados y activistas que manifiesten inclinaciones violentas en sus discursos y en sus comportamientos. Se trata de atajar y reprimir el recurso a la fuerza en sus primeros estadios. Del mismo modo, el trabajo de prevención se centrará en detectar y neutralizar los movimientos de quienes pretenden adoctrinarles y reclutarles para sus fines.

Los doblemente agraviados son el grupo más difícil de tratar por las políticas que pretenden prevenir la radicalización violenta. Todo lo dicho para el segmento de los altruistas es de aplicación para este tipo, a lo que cabría añadir dos líneas más. En primer lugar, controlar y neutralizar los intentos de las élites que les señalan directa o indirectamente el camino a seguir. El poder judicial debe intervenir, sin menoscabo de la libertad de expresión y del libre ejercicio de los derechos políticos, para enjuiciar y sancionar las conductas de los líderes políticos, sociales y religiosos que llaman a los jóvenes al uso de la fuerza en las causas que les afectan y con las que se identifican.

En segundo lugar, aplicar programas de desenganche de la violencia ante las primeras evidencias de que recurren a la fuerza para sus fines. Los jóvenes de este segmento plantean un verdadero desafío a los programas de desradicalización por su doble orientación hacia la violencia y la solidez de los compromisos que adquieren.

\section{Conclusiones}

La tipología y la escala de riesgo de radicalización o desarrollo de comportamientos violentos propuesta permite cambiar el punto de partida de las políticas de prevención de la radicalización violenta de la juventud y pasar el acento desde las ideologías políticas, religiosas y político-religiosas a las acciones. Como se describe en el marco teórico, diferentes autores y también, la política europea de prevención de la radicalización, y como consecuencia de ella, la española, entienden la radicalización como un proceso que se inicia abrazando ideas y valores extremistas que, en determinadas circunstancias, pueden terminar defendiéndose por medios violentos. En ese modelo, las ideas son el motor hacia la violencia, luego la prevención tiene que ver con controlar la difusión de es- 
tas en sus versiones más extremista e intervenir sobre las circunstancias que coadyuvan a su defensa por la fuerza.

Este trabajo avanza en la alteración de esa cadena causal de la política pública y comenzar por la disposición/predisposición a la violencia entendida no como un comportamiento irracional o agresivo sino como consecuencia de una cultura y sistema de valores que legitima y en ocasiones, promueve, su utilización. En este sentido, los resultados de la encuesta muestran que hay personas más dispuestas que otras a usar la fuerza para defender sus ideas y sus intereses, esa disposición se potencia y activa en determinadas circunstancias, luego la política de prevención de la radicalización violenta consistirá en detectar a las personas con alta predisposición al uso de la violencia e intervenir sobre las circunstancias que conducen a que esa disposición se transforme en comportamientos violentos, sean cuales sean las ideas e intereses que les movilicen.

La ventaja principal de este cambio es que permite organizar políticas de prevención de la radicalización que no se vinculan con el control de las ideas radicales ya sean políticas, religiosas, o de otro género, control que resulta polémico en los sistemas democráticos, además de poco eficaz. Colocar la cuestión de la violencia en el centro de las políticas facilita la obtención de apoyos a las medidas que se adopten, al vincular directamente la prevención de la radicalización con un fin sine qua non del estado: asegurar el monopolio del uso legítimo de la violencia.

Así, este trabajo se sitúa en la línea de los autores que buscan reducir el riesgo de estigmatizar a este o aquel colectivo, como sucede con algunos programas de prevención de la radicalización violenta que, sin pretenderlo, acaban extendiendo sospechas sobre el conjunto de personas que comparten una ideología, una posición política o unas creencias religiosas determinadas.

En otro orden de cosas, esta tipología abre el foco de atención de las políticas de prevención añadiendo a la cuestión de las ideas - disposición socio-trópica a la violencia- el tema de los intereses -disposición egocén- trica-, como espacio en que se recurre con frecuencia a la violencia y con consecuencias graves siendo, por tanto, un asunto relevante que debiera incorporarse a las políticas preventivas.

Emplear una tipología permite diferenciar fenómenos que pueden parecer similares al compartir algún rasgo común. Los indignados, los altruistas y los doblemente dispuestos a la violencia en ocasiones son difíciles de distinguir, dado que todos propenden a la fuerza para sus fines mostrando comportamientos parecidos. Sin embargo, representan amenazas muy distintas para la convivencia. Los indignados vierten su ira sobre los incumbentes y las decisiones que adoptan y suelen contentarse si cambian unos y otras. Los altruistas y, sobre todo, los doblemente dispuestos a la violencia cargan contra las instituciones del sistema, el propio régimen democrático y la comunidad política. Sus objetivos y los de quienes les alientan son alterar el sistema institucional, desestabilizar el régimen y fracturar la comunidad política. El desafío que plantea cada tipo es distinto por su contenido y gravedad y ha de ser tratado mediante instrumentos específicos.

Disponer de una escala facilita la posibilidad de establecer los objetivos y ajustar las respuestas de política pública a los problemas públicos. La escala de riesgo de radicalización que proponemos permite plantear dos metas diferentes para la política de prevención: impedir la radicalización al interior de cada tipo, es decir, evitar que los individuos de un segmento concreto recurran a la fuerza cada vez en mayor número, con más frecuencia y/o mayor intensidad, y dificultar el paso entre tipos: pacifistas comprometidos que devienen en altruistas; indignados que se transforman en doblemente agraviados, etc.

En lo relativo al ajuste de las respuestas también es de ayuda: los autodefensivos requieren más receptividad gubernamental y control que represión; los altruistas necesitan orientación hacia vías pacíficas, protección frente a los adoctrinadores y represión, y los doblemente agraviados, defensa ante liderazgos irresponsables, represión y programas potentes de desradicalización.

\section{Bibliografía}

Baran, Z. (2005). "Fighting the war of ideas", Foreign Affairs, 84: 68-78. DOI: http://dx.doi.org/10.2307/20031777

Bartlett, J., Birdwell, J., y King, M. (2010). The edge of violence: A radical approach to extremism. Londres: Demos.

Basra, R., Neumann, P. R., y Brunner, C. (2016). Criminal pasts, terrorist futures: European jihadists and the new crime-terror nexus. ICSR, King's College London.

Becker, H. (1940). "Constructive Typology in the Social Sciences”, American Sociological Review, 5(1): 40-55.

Bermejo, R. (2020). “Qué tienen en común las respuestas a la COVID-19 y al extremismo violento?”. The Conversation, 2 de julio, https://theconversation.com/que-tienen-en-comun-las-respuestas-a-la-covid-19-y-al-extremismo-violento-141056

Collier, D., Laporte, J., y Seawright, J. (2008). “Typologies: forming concepts and creating categorical variables”, H. E. Brady y D. Collier (ed.). The Oxford Handbook of Political Methodology. Oxford: Oxford University Press, pp. 152-173.

Crenshaw, M. (2008). "The debate over "new" vs. "old" terrorism”. En I.A. Karawan y W. McCormack y S.E. Reynolds. (ed.). Values and violence. Studies in global justice. Dordrecht. DOI: https://doi.org/10.1007/978-1-4020-8660-1_8

Crone, M. (2016). "Radicalization revisited: violence, politics and the skills of the body", International Affairs, 92 (3), $587-604$.

Gómez, A., López-Rodríguez, L., Vázquez, A., Paredes, B., y Martínez, M. (2016). "Morir y matar por un grupo o unos valores. Estrategias para evitar, reducir y/o erradicar el comportamiento grupal extremista”, Anuario de Psicología Jurídica, 6:122-129.

Hoffman, B. (2006). "Defining terrorism", en Inside Terrorism. Nueva York: Columbia University Press, pp. 1-42.

Horgan, J y Taylor, M. (2011). "Disengagement, de-radicalization and the arc of terrorism: future directions for research", en R. Coolsaet (ed.). Jihadi terrorism and the radicalisation challenge. Londres: Ashgate.

Jenkins, B. M. (2006). "The new age of terrorism”, en D. G. Kamien. (ed.). The mcgraw-hill homeland security handbook. New York: McGraw-Hill, pp. 117-130. 
Kupatadze, A., y Argomaniz, J. (2019). "Introduction to special issue - understanding and conceptualizing european jihadists: criminals, extremists or both?”, European Journal of Criminology, 16 (3): 261-277. DOI: 10.1177/1477370819829971.

Lobato, R. M., Moya, M., Moyano, M., y Trujillo, H.M. (2018). "From oppression to violence: the role of oppression, radicalism, identity, and cultural intelligence in violent disinhibition”, Frontiers in Psychology, 9: 1-11. DOI: https://doi.org/10.3389/ fpsyg.2018.01505

McCauley, C., y Moskalenko, S. (2008). "Mechanisms of political radicalization: pathways toward terrorism", Terrorism and Political Violence, 20: 3: 415-33

Moghaddam, F. M. (2005). “The staircase to terrorism: A psychological exploration”, American Psychologist, 60: 161-169. DOI: http://dx.doi.org/10.1037/0003-066X.60.2.161

Moskalenko, S., y McCauley, C. (2009). "Measuring political mobilization: The distinction between activism and radicalism", Terrorism and Political Violence, 21(2): 239-260. DOI: 10.1080/09546550902765508

Moyano, M. (2011). Factores psicosociales contribuyentes a la radicalización islamista de jóvenes en España. Tesis doctoral. Granada: Universidad de Granada.

Nesser, P. (2015). Islamist terrorism in Europe. A history. Londres: Hurst and Company.

Neumann, P. R. (2013). “The Trouble with Radicalisation”, International Affairs, 89(4): 873-893.

Rapoport, D. (1999). “Terrorism”, en L. R. Kurtz y J. E. (ed.). Turpin encyclopedia of violence, peace. London: Academic Press.

Rapoport, D. (2001). "The fourth wave: September 11 in the history of terrorism", Current History, 100 (650): $419-424$. DOI: https://doi.org/10.1525/curh.2001.100.650.419

Rapoport, D. (2004). “The four waves of modern terrorism”, En A. K. Cronin \& J. M. Ludes (ed.). Attacking terrorism: elements of a grand strategy. Washington: Georgetown University Press, pp. 46-73.

Richardson, L. (2006). "What is terrorism?", en What terrorists want, Nueva York: Random House, pp. 3-20.

Rondon, M. B. (2003). "From marianism to terrorism: the many faces of violence against women in Latin America", Arch Womens Mental Health, 6: 157-163 DOI: 10.1007/s00737-003-0169-3

Ruiz Díaz, L. J. (2017). "La prevención de la radicalización en la estrategia contra el terrorismo de la Unión Europea. Entre soft law e impulso de medidas de apoyo", Revista Española de Derecho Internacional, 69(2): 257-280.

Trujillo-Mendoza, H. M. et al. (2006). "De la agresividad a la violencia terrorista: historia de una patología psicosocial previsible (parte I)", Psicología Conductual, 14(2): 273-288

Trujillo-Mendoza, H. M. (2019). "Los procesos de radicalización off line”, en R. Bermejo y I. Bazaga (ed.). Radicalización violenta en España. Detección, gestión y respuesta. Valencia: Tirant lo Blanch, pp. 91-108.

Victoroff, J. (2005). "The Mind of the Terrorist: A Review and Critique of Psychological Approaches", Journal of Conflict Resolution, 49(1): 3-42. DOI: https://doi.org/10.1177/0022002704272040

Waldmann, P. (2007). "Is There a Culture of Violence in Colombia?, Terrorism and Political Violence, 19(4): 593-609. DOI: $10.1080 / 09546550701626836$

Wiktorowicz, Q. (2005). Radical Islam rising: muslim extremism in the West Oxford. London: Rowman \& Littlefield. 